\title{
Laminin-chitosan-PLGA conduit co-transplanted with Schwann and neural stem cells to repair the injured recurrent laryngeal nerve
}

\author{
YU LI, ZIWEI YU, YONGZHI MEN, XINWEI CHEN and BAOXIN WANG \\ Department of Otolaryngology, Head and Neck Surgery, Shanghai General Hospital, \\ Shanghai JiaoTong University School of Medicine, Shanghai 200000, P.R. China
}

Received November 6, 2015; Accepted March 10, 2017

DOI: $10.3892 /$ etm.2018.6343

\begin{abstract}
The aim of the present study was to assess the possibility and efficacy of utilizing a laminin-chitosan-poly (lactic-co-glycolicacid), otherwise known as laminin-chitosanPLGA, nerve conduit with the co-transplantation of Schwann and neural stem cells to repair peripheral nerve defects. Previous in vitro experiments have demonstrated that the three-dimensional structure of the built in fiber filament electrospinning of laminin-chitosan-PLGA nerve conduit is beneficial to the migration and regeneration of nerve cells, and has notable mechanical strength and plasticity. It is able to provide support in the neural tissue regeneration process, and has the ability to degrade itself once peripheral nerves complete their regeneration, providing more advantages than other biological and synthetic materials. In the present study, 132 female Sprague Dawley rats were used to establish an animal model of laryngeal nerve injury, and the rats were randomly divided into six groups for experimentation. The nerve conduit was prepared and co-cultured with Schwann and neural stem cells, and micro-surgical techniques were used to repair the 5-mm-long recurrent laryngeal nerve injuries. Functional and histological assessments were performed at 8 and 12 weeks post-surgery, respectively. The results revealed that the laminin-chitosan-PLGA nerve conduit combined with Schwann and neural stem cells was able to promote nerve regeneration $(\mathrm{P}<0.05)$, and its effect was superior to those of the autograft $(\mathrm{P}<0.05)$. The results of the present study suggest that this is the ideal method for
\end{abstract}

Correspondence to: Professor Ziwei Yu, Department of Otolaryngology, Head and Neck Surgery, Shanghai General Hospital, Shanghai JiaoTong University School of Medicine, 100 Haining Road, Shanghai 200000, P.R. China

E-mail: david545yu@163.com

Key words: neural stem cells, Schwann cells, laminin-chitosan-poly (lactic-co-glycolic acid), conduit, co-transplant, repair, nerve injury repairing peripheral nerve defects, and cells in the graft may promote nerve regeneration.

\section{Introduction}

Autologous nerve grafting has long been considered the gold standard for peripheral nerve defect repair (1). However, certain factors including donor material limitations, functional limitations of the donor zone, sensory axon dislocation growth, regeneration of axon dispersion, and requirements for immunosuppression therapy severely restrict its clinical application (2). Due to these limitations, there is an urgent need to find an alternative approach for repairing nerve defects and optimizing functional recovery of the injured nerve. Several techniques and materials have been tested, and one alternative was found using allografts (3). Nerve conduits made from either natural or synthetic materials are complex, having specific demerits in their three-dimensional structure and biological activity (4). These nerve conduits have been reported to be the most promising method for bridging injured peripheral nerves (5-9). For example, Meek (10) used a polyglycolic acid nerve conduit to treat 136 patients with nerve damage. The patients expressed that the restoration process was better than end-to-end nerve grafting; however, the repair was limited to $<3 \mathrm{~cm}$ in length. Suzuki et al (11) used a freeze-dried alginate conduit to repair a 50-mm cat sciatic nerve defect. Postoperative histological examination revealed newly generated nerve bundles, and the nerve conduit was completely degraded.

Schwann and neural stem cells have an important role in the repair and regeneration of peripheral nerve injury $(12,13)$. Neural stem cells are able to proliferate and differentiate into neurons, astrocytes, and oligodendrocytes in in vitro and in vivo transplantation conditions (14). Schwann cells secrete a variety of nerve growth factors, neurotrophic factors, and neurite growth factors, providing nutrition to the nerve and promoting axonal regeneration, and so are widely used in experimental studies of nerve repair $(15,16)$. A pure neural stem cell culture in vitro experiment found that although neural stem cells are able to differentiate into neural cells, the majority differentiate into oligodendrocytes and astrocytes, with few becoming neurons (17). One study using rat neural stem cells co-cultured with Schwann cells in vitro reported 
that both symbiotic and Schwann cells promote neural stem cells to differentiate into neuron-like cells (18). It has been speculated that this may be due to the interaction of several neurotrophic factors that are secreted by Schwann cells, including nerve growth factor, brain-derived neurotrophic factor (BDNF), glial cell-derived neurotrophic factor and basic fibroblast growth factor (19-21). Guo et al (22) reported that NT-3-modified Schwann cells co-transplanted with neural stem cells were better able to promote neural survival and axonal regeneration of spinal cord injuries compared with simple transplantation of Schwann or neural stem cells alone. Clinically, the repair of injured nerves requires neural stem cells to differentiate into neurons more often than usual and also that well-differentiated neurons survive and grow quickly prior to glial cells proliferation, breaking through the injured area, and establishing contact with the surrounding nerve cells (23). Schwann cells are able to secrete a variety of neurotrophic factors that induce axons to build, extend, and inhibit glial scar formation (24). Furthermore, Schwann cells promote injured nerves to repair the structures and functions of tissues, and so co-transplanting them together with neural stem cells may be beneficial for repairing peripheral nerve injuries.

Some experiment results have demonstrated that the transplantation of Schwann and neural stem cells has promising effects for the treatment of central nervous system injuries $(25,26)$. Xia et al $(25)$ cultured two types of cells into a directional PLGA scaffold and transplanted it into a spinal cord hemisection in a rat model. The results demonstrated that the scaffolds provided a good environment for the regeneration of neural stem cells and promoted the regeneration of axons, myelin formation, and recovery of motor function. Chen et al (26) reported that transplanted neural stem cells were able to survive and migrate up to 24 weeks following rat spinal cord injury, and were able to differentiate into various neural cells. Co-transplantation of cells/PLGA promotes the functional recovery of the injured spinal cord (26). The effect of co-transplanting neural stem cells and Schwann cells with PLGA is better than transplanting neural stem cells combined PLGA alone (26).

Based on these previous studies, it was presumed that nerve conduits co-cultured with Schwann and neural stem cells were able to promote the regeneration of recurrent laryngeal nerve (RLN) injuries. To test the feasibility of this hypothesis, the laminin-chitosan-PLGA nerve conduit was combined with Schwann and neural stem cells to bridge injured laryngeal nerves in SD rats and assess the regeneration of nerve structures and functions at different time points.

\section{Materials and methods}

Experimental animals. A total of 132, 40-day-old female Sprague Dawley (SD) rats (weighing $\sim 150 \mathrm{~g}$ ), provided by the Laboratory Animal Center of the First People's Hospital of Shanghai Jiao Tong University (Shanghai, China), were used to establish an animal model of laryngeal nerve injury and were randomly divided into six groups $(n=22$ in each): Co-culture of neural stem cells and Schwann cells with a laminin-chitosan-PLGA nerve conduit (CO); Schwann cells with a nerve conduit (SC); neural stem cells with a nerve conduit (NSC); nerve conduit (NULL); autologous nerve grafts (AUTOGRAFT); and sham operation (SHAM). Rats were maintained under a 12-h light/dark cycle and were provided with standard mouse chow and water ad libitum. The temperature was maintained at $18-23^{\circ} \mathrm{C}$ and humidity at $40-70 \%$. All rat experiment protocols were approved by the Ethics Committee of Shanghai General People's Hospital, affiliated to the Shanghai Jiao Tong University School of Medicine (Shanghai, China). All surgical procedures were performed under aseptic conditions following general anesthesia administration via an intraperitoneal injection of $10 \%$ choral hydrate $(400 \mathrm{mg} / \mathrm{kg}$; Sinopharm Chemical Reagent Co., Ltd., Shanghai, China).

Cell culture. A total of 10 3-to 5-day-old Wistar rats (1:1 sex ratio) were provided by the Laboratory Animal Center of the First People's Hospital of Shanghai Jiao Tong University ( $\sim 8$ g) and housed under a 12-h light/dark cycle with standard mouse chow and water ad libitum. The temperature was maintained at $18-23^{\circ} \mathrm{C}$ and humidity at $40-70 \%$. Rats were sacrificed by decapitation and the outer membrane of the sciatic nerve was gently removed under a microscope (Leica Microsystems GmbH, Wetzlar, Germany; magnification, x10), and ophthalmic scissors were used to cut the outer membrane into pieces. The enzyme digestion method was used for the primary culture (27). The culture was then purified to the second generation and identified by S100 staining at room temperature for 2 h (Dako; Agilent Technologies, Inc., Santa Clara, USA) as previously described (27).

Caesarean sections were performed on 2 SD rats (weight, $220 \mathrm{~g}$ ) provided by the First People's Hospital of Shanghai Jiao Tong University Laboratory Animal Center on gestational day 14. Rats were maintained under a 12-h light/dark cycle and were provided with standard mouse chow and water ad libitum. The temperature was maintained at $18-23^{\circ} \mathrm{C}$ and humidity at $40-70 \%$. The fetuses were obtained and decapitated, the hemispheres were separated and the olfactory bulb was removed. Diencephalon, cerebellum, and stripped vascular membrane were observed under a inverted microscope (magnification, x20). The left cerebral cortex and the hippocampus of both sides were placed in a 15-ml centrifuge tube containing neural stem cells culture medium [NSCM; DMEM/F12 (1:1; Gibco; Thermo Fisher Scientific, Inc., Waltham, MA, USA)], 2\% B-27 Supplement Minus AO (Invitrogen; Thermo Fisher Scientific, Inc.) $20 \mathrm{ng} / \mathrm{ml}$ epidermal growth factor, $20 \mathrm{ng} / \mathrm{ml}$ basic fibroblast growth factor (both PeproTech, Inc., Rocky Hill, NJ, USA), 50x L-glutamine (Sigma-Aldrich; Merck KGaA, Darmstadt, Germany) and $1 \%$ penicillin-streptomycin] and the contents were transferred to another $15-\mathrm{ml}$ centrifuge tube and blown into single-cell suspension. The contents were subsequently filtered by a $40-\mu 1$ mesh filter and seeded in the NSCM at a density of $1 \times 10^{5}$ cells $/ \mathrm{ml}$ in a $25 \mathrm{~T}$ bottle. NSCM was changed when cells had been incubated at $37^{\circ} \mathrm{C}$ in an incubator containing $5 \% \mathrm{CO}_{2}$ for 2 days. The neural stem cells were identified using nestin (BD Pharmingen; BD Biosciences, Franklin Lakes, NJ, USA) (27).

Nerve conduit preparation. Chitosan-coated PLGA conduits were supplied by Donghua University (Shanghai, China). In 
the present study, 10 nanofiber filaments were built in the nerve conduit of $0.6-\mathrm{mm}$ inner diameter, $0.2-\mathrm{mm}$ tube wall thickness, and 2-cm length.

A total of $3.5 \%$ shell syrup was used because of its low viscosity and ability to penetrate into the yarn. The composition of the chitosan syrup was as follows: $3.5 \%$ chitosan (BBI Life Sciences, Shanghai, China), $4 \%$ acetic acid, and $92.5 \%$ distilled water. Both ends of the 11-cm-long fabric conduit were fixed by two metal clips, which were immersed in a $0.1 \%$ chitosan, for $30 \mathrm{~min}$ at room temperature. The surface of the nerve conduit was gently brushed with a fine brush. Excess shell syrup was subsequently removed, and the nerve fabric conduit was dried at room temperature. The fabric was shaped in an oven at $70^{\circ} \mathrm{C}$ for 15 min (Changzhou Textile Instrument Factory Co., Ltd., (Changzhou, China). When the coating was dry and fixed, the core axis of the conduit was gently drawn out, the conduit was cut into 7-mm fragments, as per the requirements of the experiment, and disinfected. The conduits were stored in a sealed pack, and preserved at $0^{\circ} \mathrm{C}$ in a refrigerator.

Chitosan-PLGA tubes were soaked in the PEI solution $(1 \mathrm{mg} / \mathrm{ml})$ for $20 \mathrm{~min}$, and rinsed in running water twice. Subsequently, the tubes were soaked in the laminin (LN) solution $(0.2 \mathrm{mg} / \mathrm{ml})$ for another $20 \mathrm{~min}$ and rinsed in running water twice. Thus, a double layer of polyethyleneimine/LN (PEI/LN) film was formed. Repeating these steps allowed the formation of a multilayer PEL/LN film on the surface of the PLGA tubes. To maintain the activity of $\mathrm{LN}$, the whole process was carried out in an ice bath $\left(0^{\circ} \mathrm{C}\right)$.

Surgical procedure. A bilateral incision was made in the right RLN of all 132 SD rats that had previously been divided into six groups: CO, SC, NSC, NULL, AUTOGRAFT and SHAM. All rats were subsequently administered with an intraperitoneal injection of $10 \%$ chloral hydrate $(300 \mathrm{mg} / \mathrm{kg})$ under sterile conditions. Each rat was subsequently placed on the operating table and neck hair was removed using a razor. The skin in the surgical area was disinfected and, following the midline on the neck, a 2-cm-long incision was made using a scalpel, and the skin and subcutaneous tissue were exposed. Anterior muscles were dissected using a curved hemostat to expose the larynx and tracheal rings. Subsequently, $\sim 1 \mathrm{~cm}$ RLN, situated in the tracheoesophageal groove, was exposed and disassociated. Microsurgical scissors were used to cut 5-mm-long segments of the middle disassociated nerve.

In the $\mathrm{CO}$ group, the distal end of the nerve segment was plugged into the laminin-chitosan-PLGA nerve conduit up to $1 \mathrm{~mm}$. The nerve conduit and nerve segment were subsequently sutured using 10-0 sutures. A mixture of $22.5 \mu \mathrm{l}$ Matrigel (BD Biosciences, Franklin Lakes, NJ, USA), $3.75 \mu 1$ Schwann cells $\left(\sim 0.083 \times 10^{6}\right.$ cells $)$, and $3.75 \mu 1$ neural stem cells $\left(\sim 0.083 \times 10^{6}\right.$ cells) was injected into the nerve conduit. The proximal end of the nerve was treated in the same manner to give a 5-mm distance between the two broken ends of the conduit.

In the SC group, the same method was used as in the $\mathrm{CO}$ group. The only change was that a mixture of $22.5 \mu \mathrm{l}$ Matrigel and $7.7 \mu \mathrm{l}$ Schwann cells $\left(\sim 0.167 \times 10^{6}\right.$ cells) was injected into the nerve conduit. In the NSC group, the same method was used as in the $\mathrm{CO}$ group. The only change was that a mixture of $22.5 \mu \mathrm{l}$ Matrigel and $7.7 \mu \mathrm{l}$ neural stem cells $\left(\sim 0.167 \times 10^{6}\right)$ was injected into the conduit. In the NULL group, only $30 \mu 1$ Matrigel was injected into the conduit. In the AUTOGRAFT group, the proximal and distal ends of the 5-mm nerve segment were swapped, and their corresponding nerve adventitia sutured. In the SHAM group, the RLN was located along the tracheoesophagea after dissection and no further procedures were performed.

Electrophysiological examination. A total of $10 \mathrm{SD}$ rats from each group were used for this analysis at the 8th and 12 th week post-surgery. Following the induction of anesthesia (10\% chloral hydrate), an anterior midline incision was made and exposed, and the right RLN was freed. The stimulation electrode (bipolar stimulation electrode) was hooked in the proximal end of the regenerated nerve, and the recording electrode was inserted into the middle of the thyroarytenoid muscle via the cricothyroid membrane. Waveforms were recorded using a Medtronic Keypoint electromyography machine (Medtronic, Minneapolis, MN, USA), and the latency and amplitudes were calculated and compared.

Electron microscopy examination. One SD rat was randomly selected from each group at 8 and 12 weeks post-surgery for toluidine blue staining and transmission electron microscopy analysis. Following anesthesia (10\% chloral hydrate), the intermediate segment of the regenerated nerve was cut and fixed in $2.5 \%$ glutaraldehyde at $4^{\circ} \mathrm{C}$ for $2 \mathrm{~h}$. Subsequently, the segment was dehydrated in graded ethanol and embedded in epoxy resin. Later, the epoxy-embedded tissue was cut into ultrathin sections $(1 \mu \mathrm{m})$ using citrate staining (H7650; Hitachi Ltd., Tokyo, Japan), and the thickness of the myelin sheath and the diameter of the myelinated nerve fiber were measured using an electron microscope. All images were processed using IPP software (version 6.0; Media Cybernetics, Inc., Rockville, MD, USA).

Statistical analysis. All data are expressed as the mean \pm standard deviation and all statistical analyses were performed using GraphPad Prism software (version 6.0; GraphPad Software, Inc., La Jolla, CA, USA). Unpaired t-test with equal standard deviation was used to test the differences between two samples in a group at various time points. $\mathrm{P}<0.05$ was considered to indicate a statistically significant difference.

\section{Results}

Cell culture. Previous in vitro results revealed that Schwann cells were S100-positive (green), and fibroblasts revealed only blue DAPI staining (14,28-30). When passaged to P2 generation, only Schwann cells were visible with few to no fibroblasts (Fig. 1). The P2 generation of neural stem cells was nestin-positive (red) under the microscope, and it can be observed that neural stem cells formed suspended spheres with nonadherent growth (Fig. 2). These indicated that the cultivation of Schwann and neural stem cells were successful.

Animal model. Surgery was successful in all groups (Fig. 3). The immediate post-surgical laryngoscopy revealed that the 

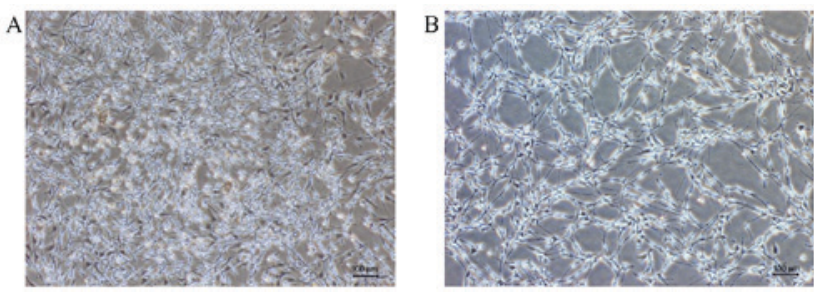

Figure 1. Schwann cell morphology under phase contrast microscopy. (A) Primary cell; cells are spindle shaped, cell bodies are small and there are many impurities. (B) Schwann cells passaged to 2nd generation; cells are purer and contain fewer fibroblasts. Scale bar $=100 \mu \mathrm{m}$.
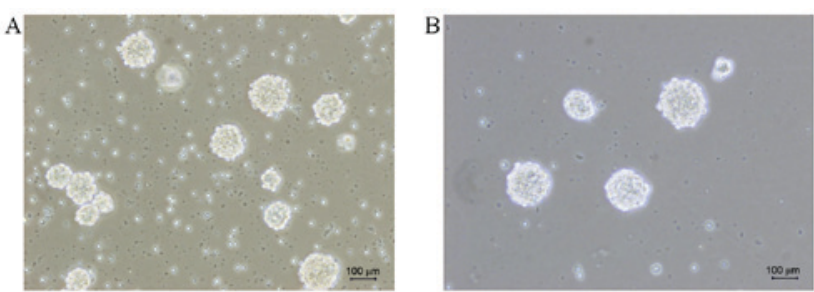

Figure 2. (A) Neural stem cell morphology under phase contrast microscopy. (A) Primary cell with some floating neural stem cell masses. (B) Neural stem cell passaged to 2 nd generation, cell masses are bigger and denser, Scale bar $=100 \mu \mathrm{m}$
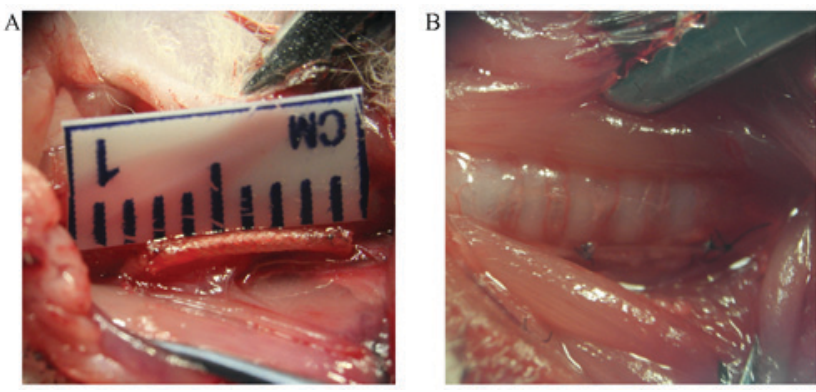

Figure 3. Surgical images. (A) Sides of the nerve stump connected with nerve conduit $(0.5 \mathrm{~cm})$ in CO, SC, NSC and NULL groups. (B) The sides of the removed nerve fragment were switched and sutured to the bilateral nerve stump in the AUTOGRAFT group. CO, co-culture of neural stem cells and Schwann cells with a laminin-chitosan-poly(lactic-co-glycolic acid) nerve conduit; SC, Schwann cells with a nerve conduit; NSC, neural stem cells with a nerve conduit; NULL, nerve conduit; AUTOGRAFT, autologous nerve grafts
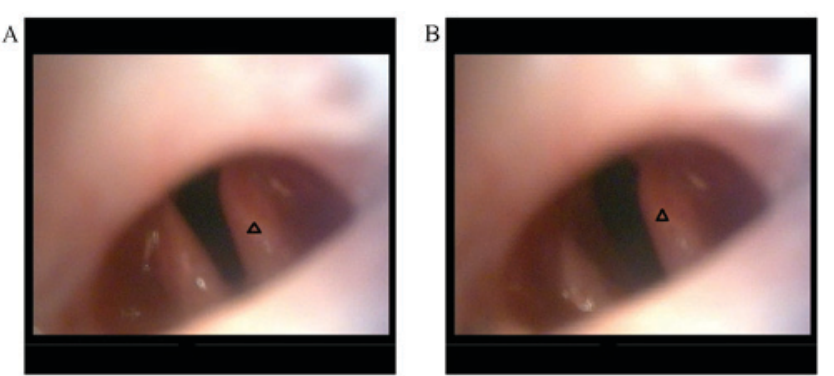

Figure 4. Immediate post-surgical laryngoscopy revealed that the vocal cord on the operative side (triangle) was fixed in place, whereas the opposite side had good movement. (A) Closure phase and (B) open phase.

vocal cord on the operative side was immovable, whereas the other side had good movement (Fig. 4), indicating successful
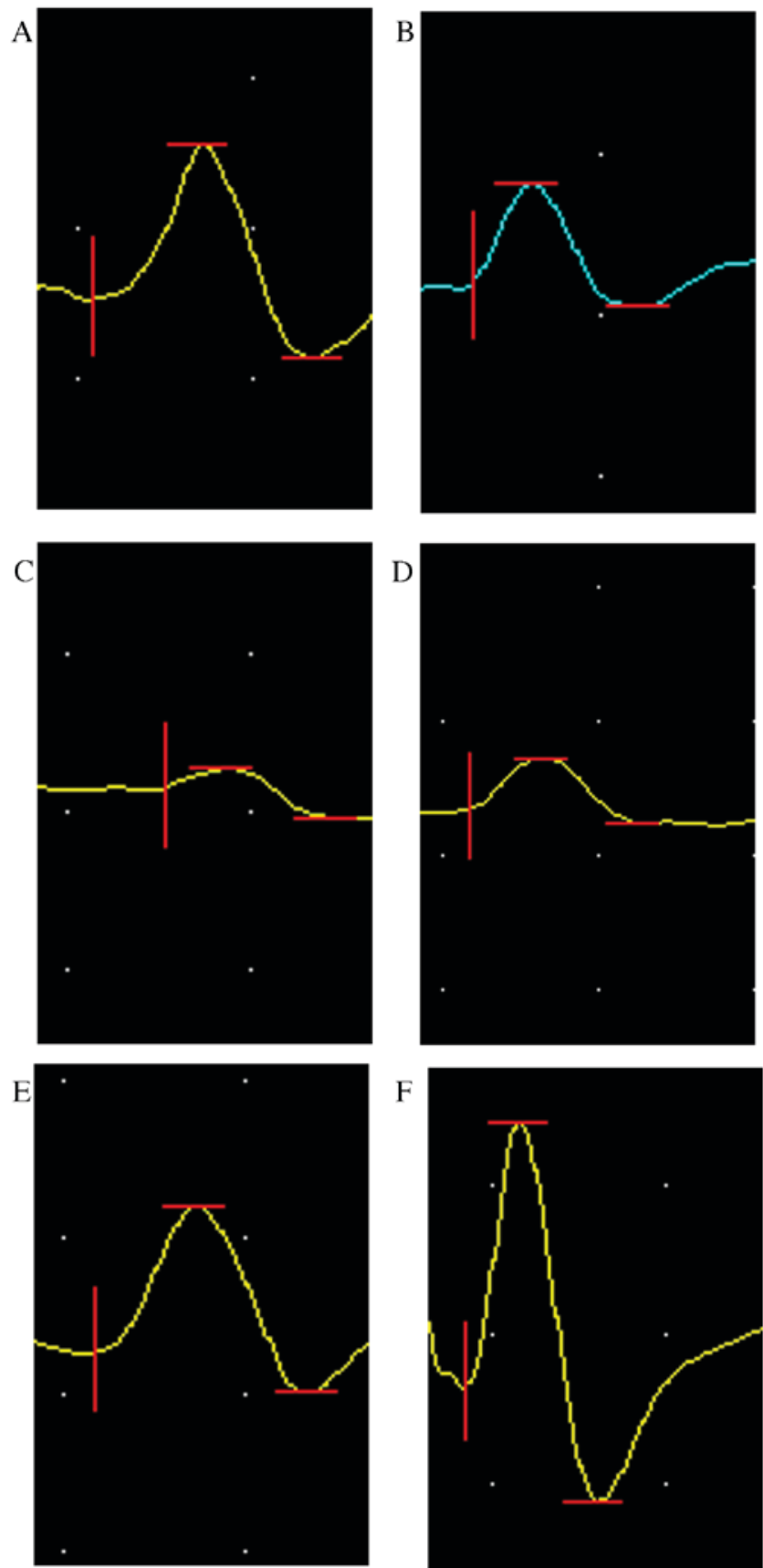

Figure 5. Representative thyroarytenoid muscle electromyography of each group at 8 weeks post-surgery. (A) co-culture of neural stem cells and Schwann cells with a laminin-chitosan-poly(lactic-co-glycolic acid) nerve conduit, (B) Schwann cells with a nerve conduit, (C) neural stem cells with a nerve conduit, (D) nerve conduit, (E) autologous nerve grafts groups and (F) sham operation groups.

establishment of animal models. All experimental animals survived without any complications, including infections. Surgical wounds healed well.

Nerve conduit. Surgical areas were re-exposed at 8 and 12 weeks post-surgery to observe the RLN conduit bridging defects. At 8 weeks, the catheter appeared thinner in all the experimental groups with some meager vascular membranes observed on the surface of the nerve conduit. No adhesion was observed between the conduit and the surrounding muscles. 

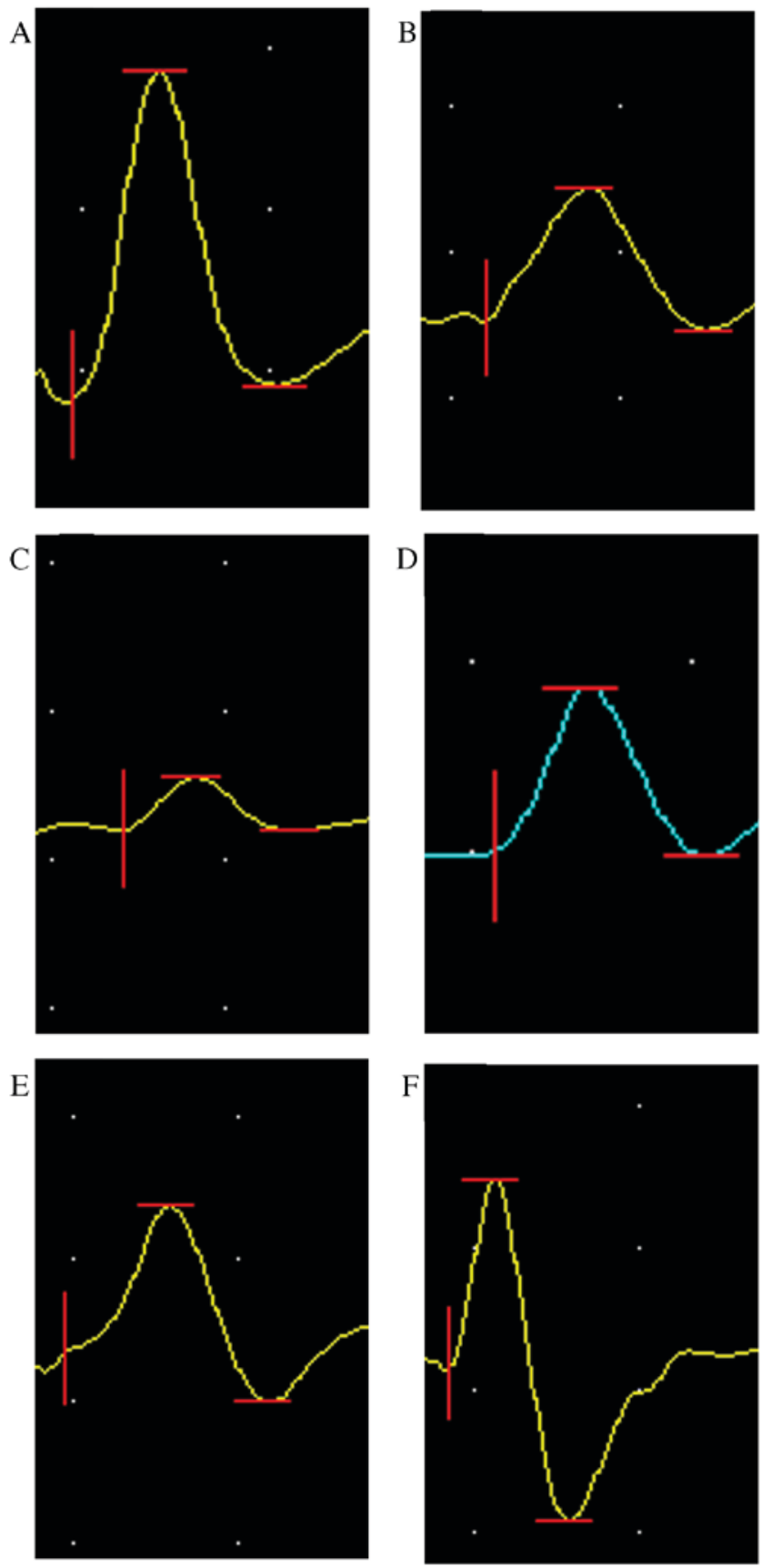

Figure 6. Representative electromyography waveform of each group at 12 weeks post-surgery. (A) co-culture of neural stem cells and Schwann cells with a laminin-chitosan-poly(lactic-co-glycolic acid) nerve conduit, (B) Schwann cells with a nerve conduit, (C) neural stem cells with a nerve conduit, (D) nerve conduit, (E) autologous nerve grafts groups and (F) sham operation groups.

At week 12, the nerve conduit in the CO group was wrapped with fibrous connective tissues, with no adhesion to surrounding tissue. The conduit became thinner, with newly formed blood capillaries on its surface. The connection of the nerve tissues was intact. Incising the conduit longitudinally revealed newly generated RLN connecting the proximal nerve to the distal nerve ends. The diameter of the middle part of the regenerated conduit was observed to be slightly smaller than the normal nerve. No obvious scars or swelling were observed

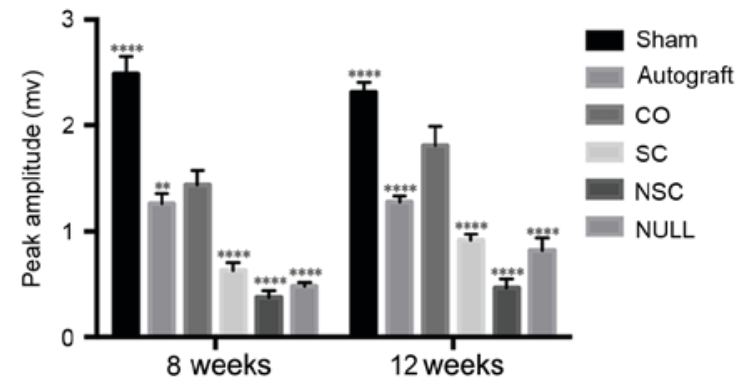

Figure 7. Peak amplitudes of SHAM, AUTOGRAFT, CO, SC, NSC, and NULL groups were calculated and statistically analyzed at 8 and 12 weeks post-surgery. ${ }^{* *} \mathrm{P}<0.01$ and ${ }^{* * * * *} \mathrm{P}<0.0001$ vs. $\mathrm{CO}$ group. $\mathrm{CO}$, co-culture of neural stem cells and Schwann cells with a laminin-chitosan-poly(lactic-co -glycolic acid) nerve conduit; SC, Schwann cells with a nerve conduit; NSC, neural stem cells with a nerve conduit; NULL, nerve conduit; AUTOGRAFT, autologous nerve grafts; SHAM, sham operation.

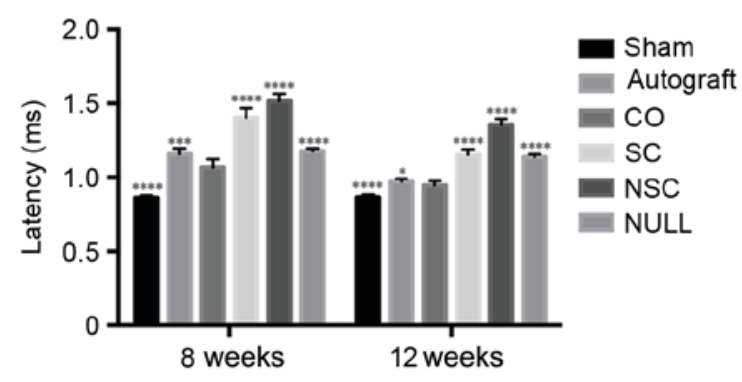

Figure 8. Latency of SHAM, AUTOGRAFT, CO, SC, NSC, and NULL groups was calculated and statistically analyzed 8 and 12 weeks post-surgery, respectively. ${ }^{*} \mathrm{P}<0.05,{ }^{* * * *} \mathrm{P}<0.001$ and ${ }^{* * * *} \mathrm{P}<0.0001$ vs. $\mathrm{CO}$ group. $\mathrm{CO}$ co-culture of neural stem cells and Schwann cells with a laminin-chitosanpoly(lactic-co-glycolic acid) nerve conduit; SC, Schwann cells with a nerve conduit; NSC, neural stem cells with a nerve conduit; NULL, nerve conduit; AUTOGRAFT, autologous nerve grafts; SHAM, sham operation.

on the nerve connection, and nerve conduit body neoplasia was not observed.

No significant atrophy was found in the muscle and muscle thyroarytenoid after freeing the throat body. Local swelling was observed in the neural stem cell group, which was surrounded by fibrous connective tissue. Mild adhesion was observed in the autograft group and nerve anastomosis was smooth without any swelling. The transplanted nerve was intact and had a soft texture.

Electrophysiological evaluation. Thyroarytenoid muscle electromyography (EMG) test results at 8 and 12 weeks post-surgery are presented in Figs. 5-8. The amplitude of the CO group was lower compared with the SHAM group $(\mathrm{P}<0.0001$; Fig. 7); however, it was significantly higher than all other groups $(\mathrm{P}<0.01$; Fig. 7). The amplitude of $\mathrm{CO}$ group at 12 th week recovered to $70 \%$ of that of the SHAM group. At weeks 8 and 12, the $\mathrm{CO}$ group had a longer latency period $(\mathrm{P}<0.0001$; Fig. 8) compared with the SHAM group and a shorter period compared with all other groups $(\mathrm{P}<0.05$; Fig. 8).

Electron microscopy. The electron microscopy examination results at 8 and 12 weeks post-surgery are displayed in 

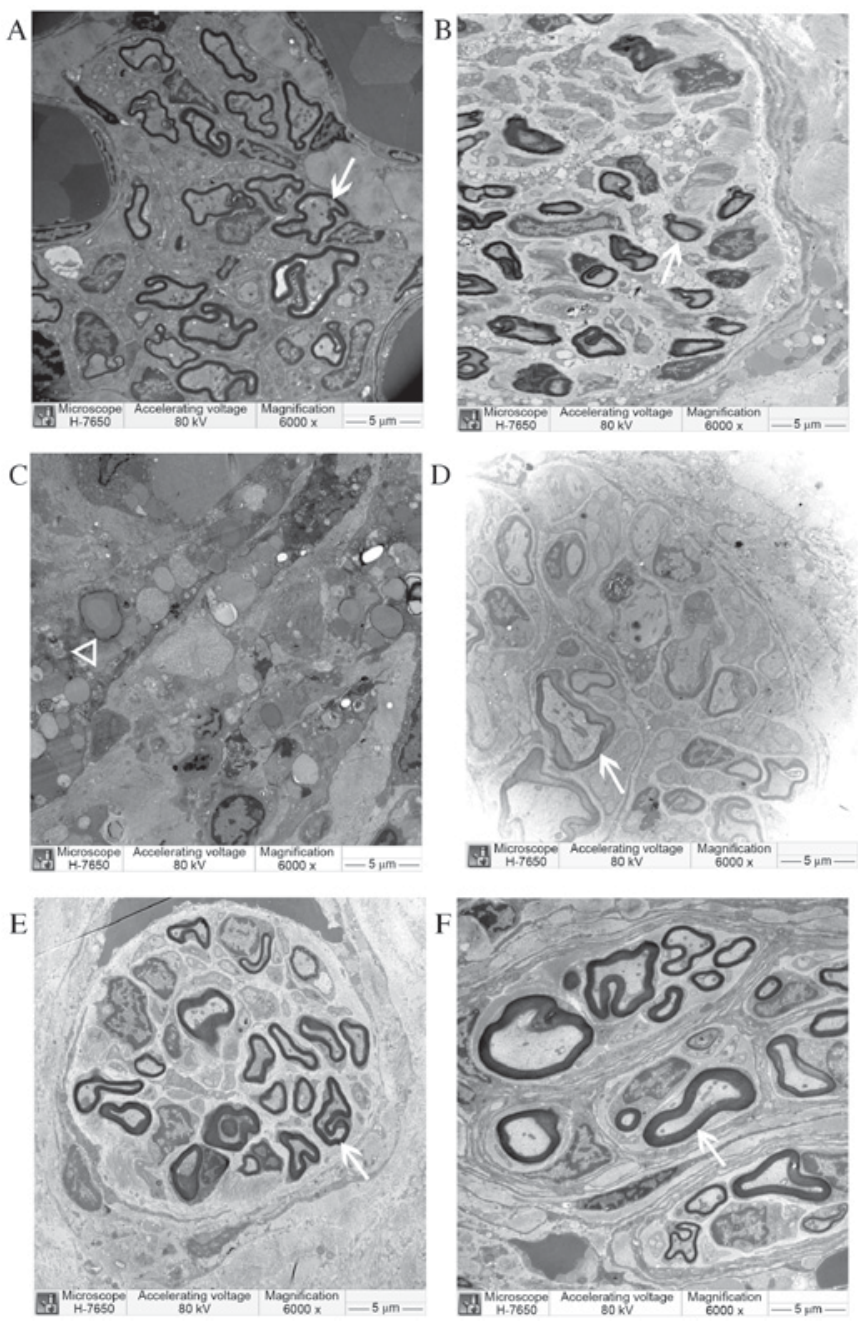

Figure 9. Semi-thin cross-sections of regenerating laryngeal nerves of (A) CO, (B) SC, (C) NSC (D) NULL, (E) AUTOGRAFT and (F) sham operation groups under electron microscopy at 8 weeks post-surgery. New myelin sheath (arrow) was observed under an electron microscope in CO, SC, NULL and AUTOGRAFT groups. In the NSC group, unabsorbed Matrigel (triangle) was observed, but no myelin sheath. Magnification, x6,000. CO, co-culture of neural stem cells and Schwann cells with a laminin-chitosan-poly (lactic-co-glycolic acid) nerve conduit; SC, Schwann cells with a nerve conduit; NSC, neural stem cells with a nerve conduit; NULL, nerve conduit; AUTOGRAFT, autologous nerve grafts.

Figs. 9 and 10. At 8 weeks post-surgery, a large number of regenerated nerve fibers were observed in the $\mathrm{CO}$ group. They were thick with a thick myelin sheath and had less connective tissue between the beams. The regenerated myelin sheath matured well with consistent thickness. Regenerated axons also developed well and were arranged in an orderly manner. Regenerated nerve fibers in the SC and NULL groups were smaller; they were scattered, twisted, and irregular, and the myelin sheath was thinner. A large amount of connective tissue, inflammatory cells, fragmentation of nuclei, and unabsorbed Matrigel were observed in the conduit of the NSC group. However, no significant newly generated myelin was observed. The regenerated myelin sheath was markedly thicker in the CO group than in other groups; however, the sheath was thinner in the $\mathrm{CO}$ group compared with the AUTOGRAFT and SHAM groups.
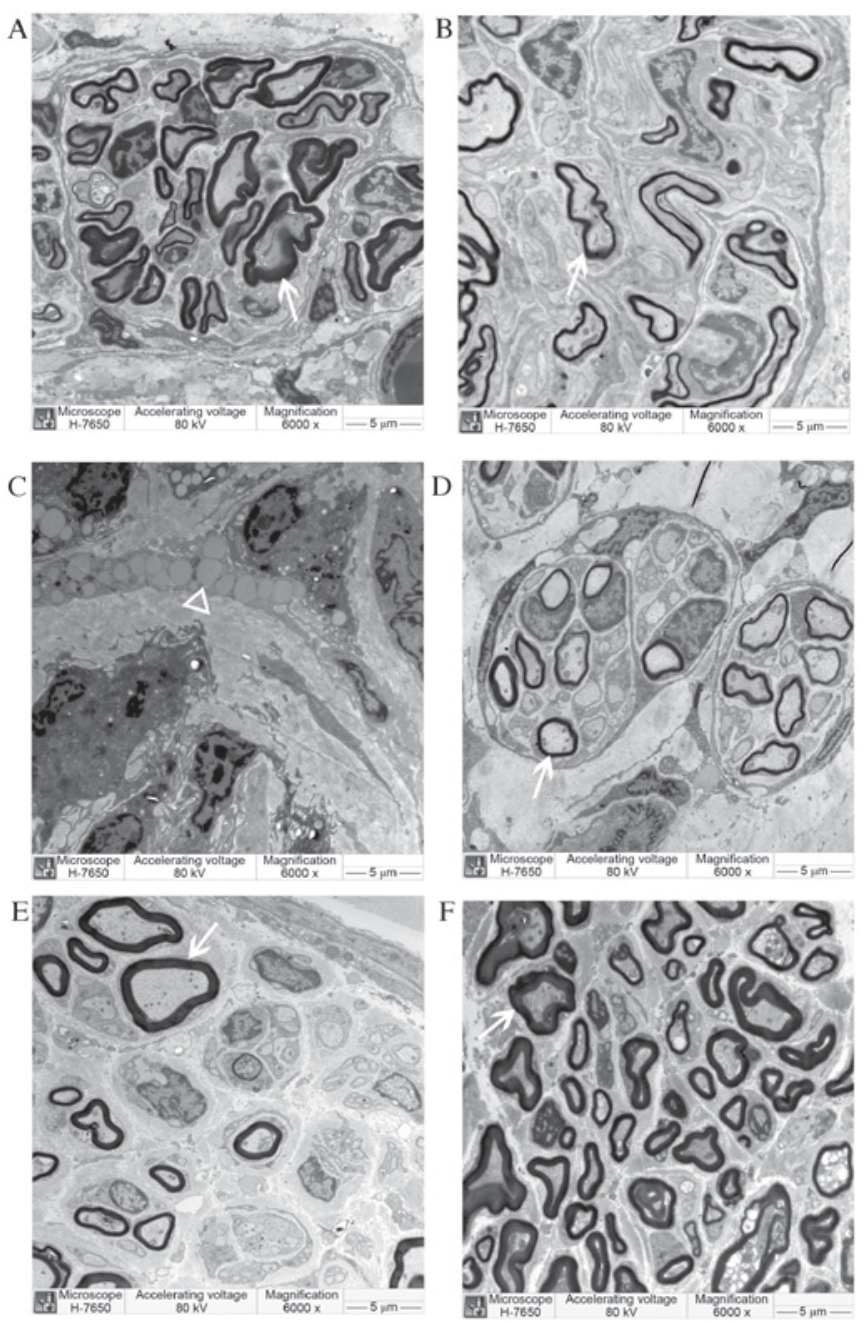

Figure 10. Semi-thin cross-sections of regenerating laryngeal nerves of (A) CO, (B) SC, (C) NSC (D) NULL, (E) AUTOGRAFT and (F) sham operation groups under electron microscopy at 12 weeks post-surgery. The newly regenerated myelin sheath (arrow) was observed in the CO, SC, NULL and AUTOGRAFT groups. In the NSC group, only unabsorbed Matrigel (triangle) was observed. Magnification, x6,000. CO, co-culture of neural stem cells and Schwann cells with a laminin-chitosan-poly(lactic-co-glycolic acid) nerve conduit; SC, Schwann cells with a nerve conduit; NSC, neural stem cells with a nerve conduit; NULL, nerve conduit; AUTOGRAFT, autologous nerve grafts.

\section{Discussion}

To resolve peripheral nerve defects, various materials including collagen, silk, cellulose, veins, muscles, and other manufacturing nerve conduits have been used to bridge nerve damage; however, no effective substitute for nerve graft has been identified that can be widely used in clinics (31). The laminin-chitosan-PLGA nerve conduits used in the present study were made by the Donghua University. The specific thermal setting process made the structure more stable, the built-in nanofiber filaments supported the conduit, and the conduits had a certain compressive strength and elasticity. Preliminary results demonstrated that laminin-chitosan-PLGA exhibited good adhesion with Schwann and neural stem cells. $\mathrm{LN}$ protein is one of the main components of the extracellular matrix (32). Recently, a number of studies in the field of 
organ development have reported that $\mathrm{LN}$ protein is able to induce differentiation of embryonic stem cells and neural stem cells (33). This suggests that laminin-chitosan-PLGA conduit is a good choice for repairing peripheral nerve damage.

Previous experimental results have demonstrated that EMG is useful for evaluating the degree of nerve regeneration (34), as the amplitude correlates with the number of muscle fibers. If a nerve is injured, some nerve fibers will be unable to transmit the nerve impulse, and the amplitude and latency will be affected (35-38). The waveform amplitude was proportional to the degree of damage following injury to the RLN; that is, the more serious the nerve injury, the smaller the amplitude, to the point where no waveform is observed. However, the latency is inversely proportional to the degree of nerve damage. The present experimental results demonstrated that the amplitude was significantly higher in the CO group compared with other groups, with the exception of the SHAM group. Furthermore, latency was significantly shorter in the $\mathrm{CO}$ group compared with all other groups, except for the SHAM group. These results suggest that nerve recovery was superior in the $\mathrm{CO}$ group when compared with the SC, NSC, NULL, and AUTOGRAFT groups.

In a separate neural stem cell + conduit group, a large number of fibroblasts, unabsorbed Matrigel, inflammatory cells, and fragmentation of cell nucleus caused by the death of neural stem cells were observed. It has been reported that neural stem cells have a low survival rate after transplantation in vivo; An et al (39) reported that Schwann cell secretions significantly support the growth of human neural stem cells; however, if they lose the support of Schwann cell secretions, nerve stem cells gradually die. This suggests that the demand for neural stem cells on local micro-environmental requirements is higher, and cultured alone they may easily die. Schwann cells in the CO group are able to secrete neurotrophic factors that prevent neural stem cell death and induce differentiation into neurons.

The results of the present study suggest that Schwann and neural stem cells co-cultured and transplanted with a nerve conduit are effective at repairing RLN injuries in rats. The conduit provides a good microenvironment for planted nerve cells and promotes axonal regeneration and myelination.

Before these findings can be applied clinically, there are some limitations to be addressed. Firstly, the approach of establishing animal models and assessing the regenerated nerve varies and lacks uniform standards. This makes it difficult to directly compare the results of different studies. Furthermore, obtaining enough Schwann cells of high purity, with high biological activity, no immune rejection, and limited proliferation is difficult. The in vitro culture, amplification, and purification of Schwann cells is complicated, and they have been reported to rapidly lose their phenotypic characteristics (40-49). As the passage number increases, the form and function of Schwann cells may change significantly. The results of the present study demonstrated that various types of stem cells have the potential ability to differentiate into Schwann-like cells and may assist in peripheral nerve regeneration. For example, adipose tissue-derived stem cells, skin mesenchymal precursors, human umbilical cord-derived mesenchymal stem cells, embryonic stem cell-derived neural crest cells, human embryonic stem cell-derived neurospheres, and amniotic mesenchymal stem cells and mesenchymal stem cells have all been reported to have this ability (40-49). A study by Dezawa (50) revealed that bone marrow stromal cells can be induced and differentiated into Schwann cells, promoting regeneration of the peripheral nervous system in a rat model. Based on these reports, stem cells are expected to become an important source of Schwann cells.

At present, many studies are in the experimental stage using animal models, and there is a big difference between in vitro and in vivo experiments. Zhang et al (51) observed that when Schwann and neural stem cells differentiated into nerve cells, morphological and functional detection demonstrated good results; however, in in vivo experiments they found that the in vitro pre-induction only slightly promoted the differentiation of neural stem cells. Therefore, to apply the results obtained from animal or in vitro experiments in a clinical setting, further research is required.

Although autologous nerve grafting is still an option, the use of a nerve conduit with co-cultured neural stem cells and Schwann cells was found to be superior in terms of the electrophysiological recovery and myelin sheath thickness of the regenerated nerve. If other neurotrophic factors were added to future experiments and the suturing techniques were improved, nerve repair may continue to advance. Further testing should also be utilized, such as using immunofluorescence, using reverse transcription polymerase chain reaction to detect BDNF RNA expression of the regenerated nerve and muscle, and observing vocal movement using a laryngoscope. To the best of our knowledge, cellular and molecular therapies directed at peripheral nerve repair have not yet advanced beyond the laboratory stage, and their translation to a clinical setting has been beset with challenges, such as the type and quantity of cells or factors and their delivery, cell viability or factor activity, cell phenotypic stability, timing of treatment, regulatory issues, and high costs (52). Although current clinical tissue engineering technology has not fully replaced autologous nerve graft and nerve stump anastomosis, with further research, tissue engineering in the field of neural defects may offer wider clinical applications.

In conclusion, the laminin-chitosan-PLGA nerve conduit combined with co-transplantation of Schwann and neural stem cells was found to effectively promote rat RLN regeneration in the present study, both by guiding the regenerated axons and contributing cells to the reconstruction.

\section{Acknowledgements}

This study was supported by the National Natural Science Foundation of China (grant no. 81170925). The authors would like to thank Donghua University, College of Textiles for their technical support.

\section{References}

1. Zhu L, Liu T, Cai J, Ma J and Chen AM: Repair and regeneration of lumbosacral nerve defects in rats with chitosan conduits containing bone marrow mesenchymal stem cells. Injury 46: 2156-2163, 2015.

2. Sinis N, Haerle M, Becker ST, Schulte-Eversum C, Vonthein R, Rösner H and Schaller HE: Neuroma formation in a rat median nerve model: Influence of distal stump and muscular coating. Plast Reconstr Surg 119: 960-966, 2007.

3. Gu X, Ding F, Yang Y and Liu J: Construction of tissue engineered nerve grafts and their application in peripheral nerve regeneration. Prog Neurobiol 93: 204-230, 2011. 
4. Arslantunali D, Dursun T, Yucel D, Hasirci N and Hasirci V: Peripheral nerve conduits: Technology update. Med Devices (Auckl) 7: 405-424, 2014.

5. Siemionow M and Sonmez E: Nerve allograft transplantation: A review. J Reconstr Microsurg 23: 511-520, 2007.

6. Brooks DN, Weber RV, Chao JD, Rinker BD, Zoldos J, Robichaux MR, Ruggeri SB, Anderson KA, Bonatz EE, Wisotsky SM, et al: Processed nerve allografts for peripheral nerve reconstruction: A multicenter study of utilization and outcomes in sensory, mixed, and motor nerve reconstructions. Microsurgery 32: 1-14, 2012.

7. Tang P, Kilic A, Konopka G, Regalbuto R, Akelina Y and Gardner T: Histologic and functional outcomes of nerve defects treated with acellular allograft versus cabled autograft in a rat model. Microsurgery 33: 460-467, 2013.

8. Brya DJ, Holway H, Wang KK, Silva AE, Trantolo DJ, Wise D and Summerhayes IC: Influence of glia growh factor and Schwann cells in a bioresorbable guidance channel on periphera nerve regeneration. Tissue Eng 6: 129-138, 2000.

9. Evans GR, Brandt K, Nidebichler AD, Chauvin P, Herrman S, Bogle M, Otta L, Wang B and Patrick CW Jr: Clinical long-term in vivo evaluation of poly(l-lactic aid) porous conduits for peripheral nerve regeneration. J Bioater Sci Polym Ed 11: 869-878, 2000.

10. Meek MF: A randomized prospective study of polyglycolic acid conduits for digital nerve reconstruction in humans. Plast Reconstr Surg 108: 1087-1088, 2001.

11. Suzuki Y, Tanihara M, Ohnishi K, Suzuki K, Endo K and Nishimura Y: Cat peripheral nerve regeneration across $50 \mathrm{~mm}$ gap repaired with a novel nerve guide composed of freeze-dried alginate gel. Neurosci Lett 259: 75-78, 1999.

12. Dong MM and Yi TH: Stem cell and peripheral nerve injury and repair. Facial Plast Surg 26: 421-427, 2010.

13. Ma MS, Boddeke E and Copray S: Pluripotent stem cells for Schwann cell engineering. Stem Cell Rev 11: 205-218, 2015.

14. Sher F, Rössler R, Brouwer N, Balasubramaniyan V, Boddeke E and Copray S: Differentiation of neural stem cells into oligodendrocytes: Involvement of the polycomb group protein Ezh2. Stem Cells 26: 2875-2883, 2008.

15. Ansselin AD, Fink T and Davey DF: Peripheral nerve regeneration through nerve guides seeded with adult Schwann cells. Neuropathol Appl Neurobiol 23: 387-398, 1997.

16. Mimura T, Dezawa M, Kanno H, Sawada H and Yamamoto I: Peripheral nerve regeneration by transplantation of bone marrow stromal cell-derived Schwann cells in adult rats. J Neurosurg 101: 806-812, 2004

17. Carpenter MK, Cui X, Hu ZY, Jackson J, Sherman S, Seiger A and Wahlberg LU: In vitro expansion of a multipotent population of human neural progenitor cells. Exp Neurol 158: 265-278, 1999.

18. Wan H, An Y, Zhang Z, Zhang Y and Wang Z: Differentiation of rat embryonic neural stem cells promoted by co-cultured Schwann cells. Chin Med J (Engl) 116: 428-431, 2003.

19. Koh HS, Yong T, Chan CK and Ramakrishna S: Enhancement of neurite outgrowth using nano-structured scaffolds coupled with laminin. Biomaterials 29: 3574-3582, 2008

20. Huang YC, Huang CC, Huang YY and Chen KS: Surface modification and characterization of chitosan or PLGA membrane with laminin by chemical and oxygen plasma treatment for neural regeneration. J Biomed Mater Res A 82: 842-851, 2007.

21. Matsumoto K, Ohnishi K, Kiyotani T, Sekine T, Ueda H, Nakamura T, Endo K and Shimizu Y: Peripheral nerve regeneration across an $80-\mathrm{mm}$ gap bridged by a polyglycolic acid (PGA)-collagen tube filled with laminin-coated collagen fibers: A histological and electrophysiological evaluation of regenerated nerves. Brain Res 868: 315-328, 2000

22. Guo JS, Zeng YS, Li HB, Huang WL, Liu RY, Li XB, Ding Y, Wu LZ and Cai DZ: Cotransplant of neural stem cells and NT-3 gene modified Schwann cells promote the recovery of transected spinal cord injury. Spinal Cord 45: 15-24, 2007.

23. Yan Hua: In vitro co culture and growth characteristics of neural stem cells and Schwann cells in combination with spinal cord injury. Med Univ Tianjin, 2003.

24. Madduri S and Gander B: Schwann cell delivery of neurotrophic factors for peripheral nerve regeneration. J Peripher Nerv Syst 15 93-103, 2010.

25. Xia L, Wan H, Hao SY, Li DZ, Chen G, Gao CC, Li JH, Yang F, Wang SG and Liu S: Co-transplantation of neural stem cells and Schwann cells within poly (L-lactic-co-glycolic acid) scaffolds facilitates axonal regeneration in hemisected rat spinal cord. Chin Med J (Engl) 126: 909-917, 2013.
26. Chen G, Hu YR, Wan H, Xia L, Li JH, Yang F, Qu X, Wang SG and Wang ZC: Functional recovery following traumatic spinal cord injury mediated by a unique polymer scaffold seeded with neural stem cells and Schwann cells. Chin Med J (Engl) 123: 2424-2431, 2010.

27. Yu Z, Men Y and Dong P: Schwann cells promote the capability of neural stem cells to differentiate into neurons and secret neurotrophic factors. Exp Ther Med 13: 2029-2035, 2017.

28. Filip S, Mokrý J, Karbanová J, Vávrová J, Vokurková J, Bláha M and English D: The transplantation of neural stem cells and predictive factors in hematopoietic recovery in irradiated mice. Transfus Apher Sci 32: 157-166, 2005.

29. Blakemore WF: The case for a central nervous system (CNS) origin for the Schwann cells that remyelinate CNS axons following concurrent loss of oligodendrocytes and astrocytes. Neuropathol Appl Neurobiol 31: 1-10, 2005

30. Heath CA: Cells for tissue engineering. Trends Biotechnol 18 $17-19,2000$

31. Kolar MK and Kingham PJ: Regenerative effects of adipose-tissue-derived stem cells for treatment of peripheral nerve injuries. Biochem Soc Trans 42: 697-701, 2014.

32. Zilic L, Wilshaw SP and Haycock JW: Decellularisation and histological characterisation of porcine peripheral nerves. Biotechnol Bioeng 113: 2041-2053, 2016.

33. Ahmad I and Akhtar MS: Use of vein conduit and isolated nerve graft in peripheral nerve repair: A comparative study. Plast Surg Int 2014: 587968, 2014.

34. Zheng H, Zhou S, Chen S, Li Z and Cuan Y: An experimental comparison of different kinds of laryngeal muscle reinnervation. Otolaryngol Head Neck Surg 119: 540-547, 1998

35. Randolph GW, Dralle H; International Intraoperative Monitoring Study Group, Abdullah H, Barczynski M, Bellantone R, Brauckhoff M, Carnaille B, Cherenko S, Chiang FY, et al: Electrophysiologic recurrent laryngeal nerve monitoring during thyroid and parathyroid surgery: International standards guideline statement. Laryngoscope 121 (Suppl 1): S1-S16, 2011.

36. Chiang FY, Lee KW, Chen HC, Chen HY, Lu IC, Kuo WR, Hsieh MC and Wu CW: Standardization of intraoperative neuromonitoring of recurrent laryngeal nerve in thyroid operation. World J Surg 34: 223-229, 2010.

37. Wu CW, Lu IC, Randolph GW, Kuo WR, Lee KW, Chen CL and Chiang FY: Investigation of optimal intensity and safety of electrical nerve stimulation during intraoperative neuromonitoring of the recurrent laryngeal nerve: A prospective porcine model. Head Neck 32: 1295-1301, 2010.

38. Chiang FY, Lu IC, Kuo WR, Lee KW, Chang NC and Wu CW: The mechanism of recurrent laryngeal nerve injury during thyroid surgery-the application of intraoperative neuromonitoring. Surgery 143: 743-749, 2008.

39. An YH, Wan H, Zhang ZS, Wang HY, Gao ZX, Sun MZ and Wang ZC: Effect of rat Schwann cell secretion on proliferation and differentiation of human neural stem cells. Biomed Environ Sci 16: 90-94, 2003

40. Banerjee A, Nürnberger S, Hennerbichler S, Riedl S, Schuh CM, Hacobian A, Teuschl A, Eibl J, Redl $\mathrm{H}$ and Wolbank S: In toto differentiation of human amniotic membrane towards the Schwann cell lineage. Cell Tissue Bank 15: 227-239, 2014.

41. Jiang TM, Yang ZJ, Kong CZ and Zhang HT: Schwann-like cells can be induction from human nestin-positive amniotic fluid mesenchymal stem cells. In Vitro Cell Dev Biol Anim 46: 793-800, 2010.

42. Kingham PJ, Kalbermatten DF, Mahay D, Armstrong SJ, Wiberg $\mathrm{M}$ and Terenghi G: Adipose-derived stem cells differentiate into a Schwann cell phenotype and promote neurite outgrowth in vitro. Exp Neurol 207: 267-274, 2007.

43. Krause MP, Dworski S, Feinberg K, Jones K, Johnston AP, Paul S, Paris M, Peles E, Bagli D, Forrest CR, et al: Direct genesis of functional rodent and human schwann cells from skin mesenchymal precursors. Stem Cell Reports 3: 85-100, 2014.

44. Lee JH, Chung WH, Kang EH, Chung DJ, Choi CB, Chang HS, Lee JH, Hwang SH, Han H, Choe BY and Kim HY: Schwann cell-like remyelination following transplantation of human umbilical cord blood (hUCB)-derived mesenchymal stem cells in dogs with acute spinal cord injury. J Neurol Sci 300: 86-96, 2011.

45. Pan Y and Cai S: Current state of the development of mesenchymal stem cells into clinically applicable Schwann cell transplants. Mol Cell Biochem 368: 127-135, 2012. 
46. Razavi S, Mardani M, Kazemi M, Esfandiari E, Narimani M, Esmaeili A and Ahmadi N: Effect of leukemia inhibitory factor on the myelinogenic ability of Schwann-like cells induced from human adipose-derived stem cells. Cell Mol Neurobiol 33: 283-289, 2013.

47. Reid AJ, Sun M, Wiberg M, Downes S, Terenghi G and Kingham PJ: Nerve repair with adipose-derived stem cells protects dorsal root ganglia neurons from apoptosis. Neuroscience 199: 515-522, 2011.

48. Ren YJ, Zhang S, Mi R, Liu Q, Zeng X, Rao M, Hoke A and Mao HQ: Enhanced differentiation of human neural crest stem cells towards the Schwann cell lineage by aligned electrospun fiber matrix. Acta Biomater 9: 7727-7736, 2013.

49. Ziegler L, Grigoryan S, Yang IH, Thakor NV and Goldstein RS Efficient generation of schwann cells from human embryonic stem cell-derived neurospheres. Stem Cell Rev 7: 394-403, 2011

50. Dezawa M: Central and peripheral nerve regeneration by transplantation of Schwann cells and transdifferentiated bone marrow stromal cells. Anat Sci Int 77: 12-25, 2002.
51. Zhang $\mathrm{X}$, Zeng $\mathrm{Y}$, Zhang W, Wang J, Wu J and Li J: Co-transplantation of neural stem cells and NT-3-overexpressing Schwann cells in transected spinal cord. J Neurotrauma 24: 1863-1877, 2007.

52. Gu Y, Zhu J, Xue C, Li Z, Ding F, Yang Y and Gu X: Chitosan/silk fibroin-based, Schwann cell-derived extracellular matrix-modified scaffolds for bridging rat sciatic nerve gaps. Biomaterials 35: 2253-2263, 2014

This work is licensed under a Creative Commons Attribution-NonCommercial-NoDerivatives 4.0 International (CC BY-NC-ND 4.0) License. 